ADALAH : Buletin Hukum \&

Keadilan

Buletin Hukum \& Keadilan

@adalahuinjkt

\title{
Wajah Buram Partai Politik
}

\author{
Ahmad Danial*
}

Dalam tatanan kehidupan berdemokrasi, salah satu aspek pendukung lancarnya distribusi nilai-nilai demokrasi agar sampai di tengah masyarakat adalah Partai Politik. Selain sebagai bentuk ekspresi dalam rangka realisasi demokrasi pancasila (demokrasi bangsa Indonesia), parpol juga dianggap sebagai penerjemah kepentingan masyarakat ke dalam regulasi yang mengatur masalah kebijakan publik. Selain dari itu, tujuan dari parpol yakni untuk memperoleh kekuasaan politik dan merebut kekuasaan dengan jalan konstitusional. Maka dari itu, baik buruknya demokrasi dalam satu negeri tergantung partai politiknya.

Ketika menilik ke dalam Black's Law Dictionary terdapat sebuah terminologi mengenai partai politik, yakni: "Political Party, an organization of voters formed to influence the goverment's conduct and policies by nominating and electing candidates to public office," Partai Politik ialah sebuah organisasi pemilih yang dibentuk untuk mempengaruhi perbuatan pemerintah dan kebijakannya dengan pencalonan dan pemilihan kandidat untuk jabatan publik (Garner, 2009: 1276). Sedang menurut Miriam Budiardjo, Partai Politik ialah suatu kelompok terorganisir yang anggotaanggotanya mempunyai orientasi, nilai-nilai dan cita-cita yang sama. Tujuan kelompok tersebut ialah untuk memperoleh kekuasaan

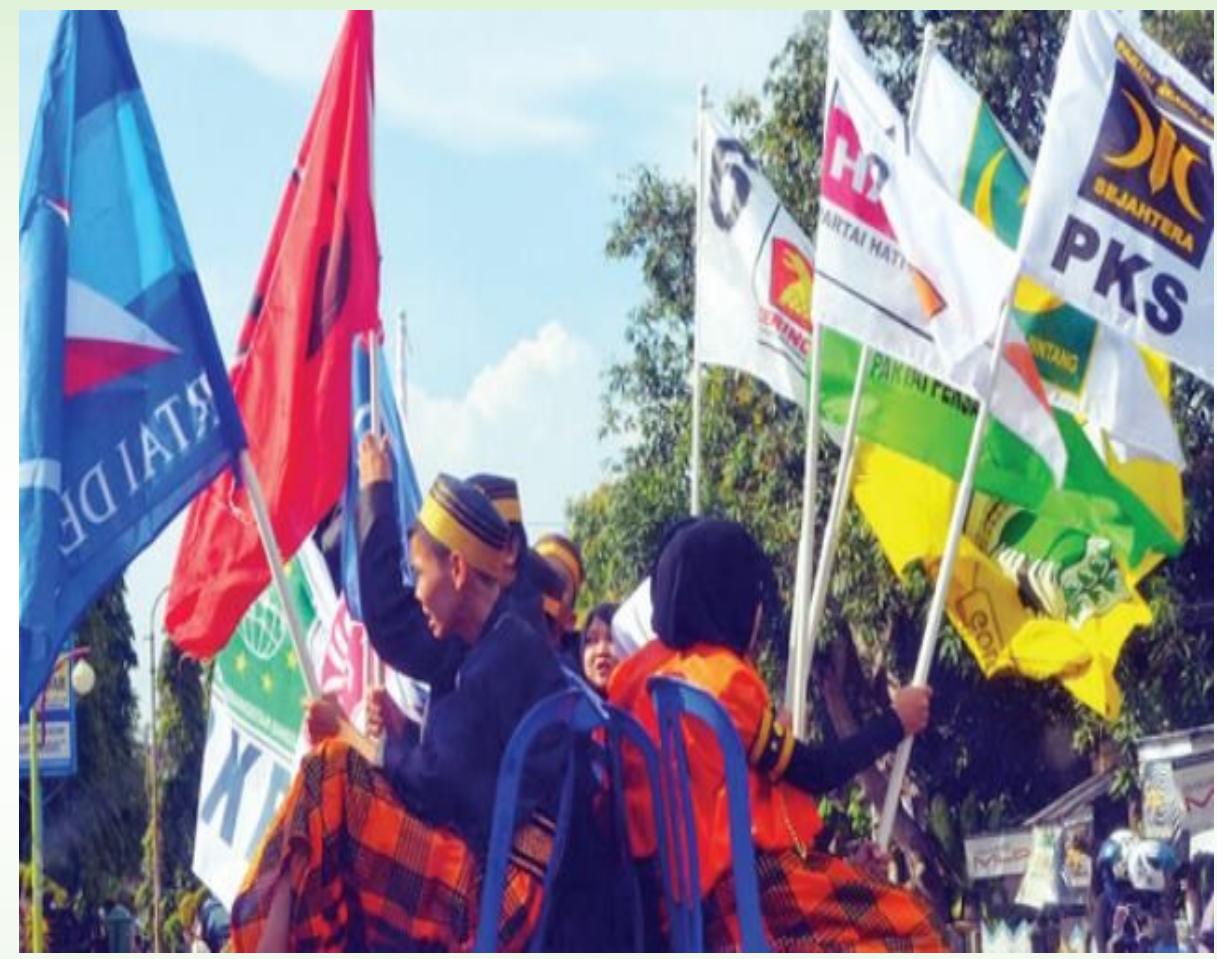

politik dan merebut kedudukan politik, biasanya dilakukan dengan cara konstitusional untuk melaksanakan programnya (Budiarjo, 1989: 403-404). Berbeda halnya Ahmad Farhan Subhi mengartikannya dengan suatu kelompok terorganisir dan teratur berdasarkan ideologi yang ikut serta atau mengambil bagian dalam Pemilu yang dilaksanakan berdasarkan kedaulatan rakyat dan diselenggarakan secara langsung, umum, bebas, rahasia, jujur, dan adil (Subhi, 2015: 345). Definisi secara yuridis juga terdapat dalam Undang-Undang Nomor 2 tahun 2008 pasal 1 ayat (1) tentang partai politik.
Jika partai politik diibaratkan sebagai organ tubuh, ia menjadi hati bagi demokrasi. Dalam hadis dijelaskan bahwa "ada segumpal daging dalam diri manusia, jika segumpal daging itu baik maka baik pula seluruh tubuhnya, sebaliknya jika segumpal daging itu buruk maka buruk pula semua tubuh itu (HR. Bukhari). Itulah perumpamaan posisi partai politik di dalam demokrasi, menentukan arah demokrasi ingin berlabuh di daratan mana? Apakah di daratan kemaslahatan umat atau di daratan kekuasaan yang kolot? Padahal sejatinya demokrasi yang menjadi dasar berpijak partai politik selalu menginginkan kebaikan pada mayoritas orang, bukan hanya 
segelintir orang saja (Yunus, 2017: 22).

Akhir-akhir ini muncul keresahan di dalam diri penulis, melihat kacau balaunya kehidupan politik negeri. Saat ini partai politik disimbolkan sebagai tumbuhan benalu yang menumpang pada sebuah pohon, alih-alih memberikan kemaslahatan, tapi malah memberikan kemudaratan yang luar biasa, karena bukannya menjadi public educator malah menjadi debtcollector, bahkan mereka dianggap sebagai pengisap darah rakyat kecil seperti saat masa kerajaan Islam pada fase kemunduran, kiri-kanan nyolong uang rakyat, kesana-kemari ngambil uang negara dan memasukkan ke kantong pribadi sedang sisanya dimasukkan di kas partai. Memang sangat miris, tapi itulah kenyataan pahit yang mau tidak mau harus diterima rakyat bahkan membuat seorang Plato dan Aristoteles galau dalam makamnya, karena mereka berdua menciptakan istilah partai politik agar distribusi keadilan sampai pada rakyat, bukan malah menjadi obat penambah sakit untuk kesengsaraan masyarakat. Entah dimana kiblat partai politik ini dalam berdiri dan berjalan ataukah mereka memang gagal paham tentang hakikat keberadaannya.

Ketika reformasi digaungkan ke seluruh antero negeri, secercah harapan muncul dari balik tabir yang kolot. Seluruh stakeholder bangsa ini berharap bahwa reformasi ini akan melahirkan kembali akal sehat yang telah lama terpasung pada rezim sebelumnya. Namun, impian itu hanya dongeng anak sebelum tidur, karena proses reformasi hanya mengubah kuantitas tidak mengubah kualitas. Karenanya, ada kebiasaan negatif dari rezim orde baru ikut terselip ke dalam keranjang piknik demokrasi. Sebab, budaya KKN malah menjadijadi, seolah-olah reformasi adalah panggung pementasan yang sangat pas. Saat membahas masalah tadi, seketika lampu sorot tertuju pada salah satu aktor penyelenggara negara, dalam hal ini parpol. Partai politik dianggap sebagai pemeran utama dari praktek penyelenggaraan negara yang menyimpang, terbukti dari beberapa kasus yang terjadi pada umumnya dilakukan oleh kader partai. Bahkan, berdasarkan fakta yang ada, mayoritas kasus korupsi adalah orang-orang yang berkecimpung di lingkungan partai politik. Ini merupakan tamparan keras betapa buruknya pola kehidupan partai politik negeri ini.

Indikasi yang ditemukan sampai hari ini adalah regulasi yang mengatur aktifitas parpol yang dianggap terlalu lemah dan memberikan ruang gerak yang bebas, sehingga dalam praktek penyelenggaraan negara mereka terlalu liar dan tidak terkontrol. Jika dibahas lebih rinci masalah utamanya adalah partai politik dibiarkan secara mandiri dalam hal mendanai partainya, sehingga dana APBN, APBD, dan dana negara yang lain dicolong habis-habisan. Sedang dalam pandangan Prof. Rocky Gerung dalam salah satu televisi swasta beberapa hari yang lalu, menganggap bahwa kultur politik negara ini masih feodal, karena salah satu ketua parpol menganggap kader partai adalah petugas partai, jadi kader partai dibrif agar mampu mengucapkan kepentingan partainya.

Suatu impian mulia yang didambakan Plato dan Aristoteles dalam merumuskan eksistensi partai politik di muka bumi ini menjadi sesuatu hal yang hampir menyentuh koridor mustahil, ketika melihat keadaan politik saat ini seolah-olah politik itu kejam dan jahat, dan menutupi nilai kemuliaan dari istilah politik itu sendiri. Langkah yang paling arif diambil atas dasar kepeduliaan terhadap kesuciaan politik adalah dengan melakukan penertiban terhadap partai politik, agar ruang gerak mereka terbatasi oleh regulasi, karena selama ini regulasi mengenai ruang gerak partai politik dianggap harus dipertegas. Maka dari itu regulasi mengenai pendanaan partai harus diatur oleh pemerintah, sehingga mereka tidak mandiri dalam hal mendanai partai. Dengan itu pemerintah mampu mengontrol partai bahkan mampu meminimalisir praktek KKN, sehingga akhirnya terciptalah tatanan politik yang sebenarnya.[]

\section{Pustaka Acuan:}

*Penulis adalah Anggota Criminal Law and Justice Community (CLJC) UIN Syarif Hidayatullah Jakarta.

Garner, Bryan A., Black's Law Dictionary, Ninth Edition, (West (USA): Thomson Reuters business, 2009).

Miriam Budiarjo, Dasar-Dasar Ilmu Politik, Jakarta: PT. Gramedia, 1989.

Subhi, Ahmad Farhan, "Pengusulan Pasangan Calon Presiden dan Wakil Presiden Sebagai Peserta Pemilu Menurut Undang-Undang Pilpres", Jurnal Cita Hukum, Vol. 3, No. 2 Desember (2015).

Yunus, Nur Rohim, Teori Dasar Penelitian Hukum Tata Negara, Jakarta: Poskolegnas, 2017.

'Adalah; Buletin Hukum dan Keadilan merupakan berkala ilmiah yang diterbitkan oleh Pusat Studi Konstitusi dan Legislasi Nasional (POSKO-LEGNAS), Fakultas Syariah dan Hukum UIN Syarif Hidayatullah Jakarta.

Penasehat: Prof. Dr. H. Abdul Ghani Abdullah, SH., Prof. Dr. H. A Salman Maggalatung, SH., MH. Pemimpin Redaktur: Indra Rahmatullah, Tim Redaktur: Nurrohim Yunus, Fathuddin, Mara Sutan Rambe, Muhammad Ishar Helmi, Erwin Hikmatiar. Penyunting: Latipah, Siti Nurhalimah. Setting \& Layout: Siti Romlah 